\title{
Paradoxical Expansion of Th1 and Th17 Lymphocytes in Rheumatoid Arthritis Following Infliximab Treatment: a Possible Explanation for a Lack of Clinical Response
}

Rossella Talotta

Angela Berzi 2

Fabiola Atzeni 1

Alberto Batticciotto 1

Mario Clerici 3,4

Piercarlo Sarzi-Puttini

Daria Trabattoni 2,5,*

Phone +390250319678

Email daria.trabattoni@unimi.it

1 Rheumatology Unit, Department of Internal Medicine, L. Sacco University Hospital, Milan, Italy

${ }^{2}$ L. Sacco Department of Biomedical and Clinical Sciences, University of Milan, Milan, Italy

3 Department of Physiopathology and Transplantation, University of Milan, Milan, Italy

4 Don C. Gnocchi Foundation, IRCCS, Milan, Italy

5 L. Sacco Department of Biomedical and Clinical Sciences, University of Milan, Milan, Italy, Via GB Grassi 74, 20157 Milan, Italy 


\section{Abstract \\ Purpose}

The immunogenicity of anti-TNF- $\alpha$ drugs may affect their safety and efficacy. Infliximab (IFX), a chimeric monoclonal antibody, induces antibody formation in up to $60 \%$ of cases. Some studies have suggested the involvement of a Th1 response to TNF $\alpha$ blockers following immunization, but the triggering of Th17 responses has never been reported. The aim of this study is to investigate whether the immunogenicity of IFX affects the Th1, Th17 and Treg compartments in rheumatoid arthritis (RA) patients failing IFX therapy, and verify whether this may be responsible for treatment failure.

\section{Methods}

The study involved 55 patients with RA (15 treatment-naïve patients; 20 IFX responders; 20 IFX non-responders) and 10 healthy controls. PBMCs were cultured in the presence/absence of IFX, and the variations in the percentage of Th1, Th17 and Treg lymphocytes following IFX treatment were analysed.

\section{Results}

IFX-specific Th1 and Th17 responses and an increase in IL-21 production were observed in patients failing IFX $(p<0.01, p<0.05$, and $p<0.01$ respectively). In contrast, IFX incubation reduced significantly Th1 and Th17 responses and IL-21 production $(p<0.05)$ in successfully-treated subjects, but did not affect these responses in healthy controls or treatment-naïve patients.

\section{Conclusions}

RA patients may have impaired peripheral tolerance, which could favour the development of an aberrant immunological response to biological drugs. The loss of therapeutic effectiveness of IFX and the 
onset of adverse events may be due to a paradoxical activation of Th17 or Th1 lymphocytes following sensitisation, thus worsening the patients' inflammatory status.

\section{Keywords}

Rheumatoid arthritis

itmmunogenicity

ìnfliximab

Th1 lymphocytes

Th17 lymphocytes

Rossella Talotta and Angela Berzi contributed equally to this work.

\section{Introduction}

Biological agents, a group of drugs obtained by means of recombinant DNA technology, include chimeric, humanised or fully human monoclonal antibodies, proteins or receptors capable of binding specific targets. In the field of rheumatology, their targets are usually molecules that play a crucial role in maintaining inflammation (e.g. TNF $\alpha$ or CD20). As their molecular structure contains a variable percentage of allogeneic components, they often elicit immunological responses associated with adverse events or a progressive lack of efficacy [1]. However, the immunogenicity of a biological agent also depends on its route of delivery, the degree of exposure, the frequency of administration, and the concomitant use of immunosuppressive agents. The humanisation of murine monoclonal antibodies has improved their tolerability, but even fully human antibodies may induce immunogenicity in a considerable number of patients probably because of anti-idiotype antibodies recognising the unique $\mathrm{V}$ region of other immunoglobulin molecules [2].

A number of clinical reports has recently investigated whether anti$\mathrm{TNF} \alpha$ agents paradoxically activate the immune system because many autoimmune disorders have been reported during anti- TNF $\alpha$ treatment, including psoriasis, de novo developing arthritis, inflammatory bowel disease, sarcoidosis and demyelinating diseases [3]. 
Biological agents may be considered as antigens capable of activating adaptive immune responses when presented by dendritic cells to $\mathrm{T}$ lymphocytes. This might result in $\mathrm{T}$ lymphocytes differentiation into Th1, Th2, Th17 or Treg effectors, giving rise to different clinical situations. IgG, IgM and IgE antibodies against biological agents have been detected in the serum of patients with rheumatic diseases who were treated with these drugs [4-7], and seem to correlate with the likelihood of a progressive lack of efficacy or the development of adverse events [8]. Some case reports and histological studies [9] have also highlighted the involvement of Th1 responses following sensitisation to a TNF $\alpha$ blocker. However, to our knowledge, no elicitation of Th17 responses by TNF $\alpha$ blockers has been described yet.

The aim of this study was to investigate whether the immunogenicity of a biological agent may affect Th1 and Th17 responses and impair regulatory $\mathrm{T}$ cell activity. Due to its greater immunogenicity, IFX appeared the most suitable candidate among the TNF $\alpha$ blockers and was therefore chosen for our analyses.

\section{Methods}

\section{Study Population}

The study involved 55 patients with rheumatoid arthritis (RA) diagnosed on the basis of the EULAR/ACR 2010 criteria [10] and 10 healthy controls. The patients included 20 consecutive adult male and female non-responders to IFX, who were compared with 15 treatmentnaïve patients and 20 matched patients successfully treated with IFX. Prednisone $\leq 5 \mathrm{mg}$ /day was allowed provided that it had been administered at a stable dose for 4 weeks before blood sampling, as were methotrexate (at a maximum dose of $15 \mathrm{mg} /$ week) [11], salazopyrin (at a maximum dose of $6 \mathrm{~g}$ /day) and hydroxychloroquine (at a maximum dose of $400 \mathrm{mg}$ /day) provided that they had been administered at a stable dose for 6 weeks before blood withdrawal. The exclusion criteria were concomitant infections at the time of blood sampling, a vaccination in the previous 2 months $[12,13]$, immunodeficiency, the concomitant use of leflunomide or cyclosporine [14-16], haematological disorders, and atopic dermatitis due to other 
antigens. Table 1 shows the demographic characteristics of the study population.

Table 1

Demographic characteristics of the study population

\begin{tabular}{|c|c|c|c|c|}
\hline Variables & $\begin{array}{l}\text { Healthy } \\
\text { controls }\end{array}$ & $\begin{array}{l}\text { Treatment- } \\
\text { naïve } \\
\text { RA } \\
\text { patients }\end{array}$ & $\begin{array}{l}\text { RA } \\
\text { patients } \\
\text { responding } \\
\text { to IFX }\end{array}$ & $\begin{array}{l}\text { RA } \\
\text { patients } \\
\text { not } \\
\text { responding } \\
\text { to IFX }\end{array}$ \\
\hline No. & 10 & 15 & 20 & 20 \\
\hline $\begin{array}{l}\text { Mean age } \pm S D \text {, } \\
\text { years }\end{array}$ & $\begin{array}{l}43.9 \pm \\
8.3\end{array}$ & $54.8 \pm 16.2$ & $61.3 \pm 12.2$ & $57.0 \pm 12.2$ \\
\hline $\begin{array}{l}\text { Mean disease } \\
\text { duration } \pm \mathrm{SD} \text {, years }\end{array}$ & / & $2.3 \pm 3.9$ & $13.4 \pm 7.2$ & $18.1 \pm 9.5$ \\
\hline $\mathrm{F} / \mathrm{M}$ & $4 / 6$ & $12 / 3$ & $16 / 4$ & $15 / 5$ \\
\hline $\mathrm{ACPA}+$ & / & 5 & 15 & 15 \\
\hline $\mathrm{RF}+$ & / & 7 & 11 & 15 \\
\hline $\mathrm{ANA}+$ & l & 2 & 12 & 17 \\
\hline Anti-dsDNA Ab+ & / & 0 & 3 & 2 \\
\hline Anti-ENA Ab+ & / & 0 & 1 & 3 \\
\hline ACLA/LAC + & l & 0 & 1 & 2 \\
\hline $\begin{array}{l}\text { Prednisone }(2.5 \\
-10 \mathrm{mg} / \text { day })\end{array}$ & I & / & 8 & 14 \\
\hline $\begin{array}{l}\text { Methotrexate ( } 5 \\
-15 \mathrm{mg} / \text { week) }\end{array}$ & / & / & 20 & 9 \\
\hline $\begin{array}{l}\text { Hydroxychloroquine } \\
\text { (200-400 mg/day) }\end{array}$ & I & / & 3 & 5 \\
\hline NSAIDs & / & 14 & as needed & as needed \\
\hline \multicolumn{5}{|c|}{$\begin{array}{l}S D \text { standard deviation, } F \text { females, } M \text { males, } A C P A \text { anti-citrullinated-protein } \\
\text { antibodies, } R F \text { rheumatoid factor, } A N A \text { anti-nuclear antibodies, anti-dsDNA } \\
\text { anti-double stranded DNA antibodies, anti-ENA anti-extractable nuclear } \\
\text { antigen antibodies, } A C L A \text { anticardiolipin antibodies, } L A C \text { lupus } \\
\text { anticoagulant, } N S A I D S \text { non-steroidal anti-inflammatory drugs }\end{array}$} \\
\hline
\end{tabular}

http://eproofing.springer.com/journals/printpage.php?token=HK1l_RZyQ3BdgbzQnD... 31/07/2015 
The study was approved by our local Ethics Committee: the Institutional Review Board of Sacco Hospital (Milan, Italy); Protocol number: 364/2013 38AP; Deliberation number: 484. The study has been performed in accordance with the 1964 Declaration of Helsinki and its later amendments.

Written informed consent was obtained from all the patients.

\section{Isolation and Culture of PBMCs}

Peripheral blood was collected into Vacutainer tubes containing EDTA (Becton Dickinson; Rutherford, NJ, USA). PBMCs were isolated by centrifugation on lymphocyte separation medium (Cedarlane Laboratories, Burlington, NC, USA). The number and viability of PBMCs were determined by an automatic cell counter, ADAM-MC (Digital-Bio, NanoEnTek Inc., Corea). PBMC viability was typically $>$ $98 \%$.

Cell cultures were performed in RPMI 1640 plus Penicillin, Streptomycin, L-Glutamine and $10 \%$ pooled Human AB Serum (all from Euroclone, Siziano, Italy). Fresh PBMCs, at a concentration of $1 \times$ $10^{6}$ cells $/ \mathrm{mL}$ were incubated for $18 \mathrm{~h}$ with culture medium alone or in the presence of $50 \mu \mathrm{g} / \mathrm{mL}$ IFX (Remicade, Janssen Biologics, Leiden, Netherlands), or $50 \mu \mathrm{g} / \mathrm{mL}$ Human IgG1 kappa (Sigma-Aldrich, Saint Louis, Mo, USA), or $50 \mu \mathrm{g} / \mathrm{mL}$ recombinant Human IgG Fc (R\&D Systems). PWM (Lectin from Phytolacca Americana; $1 \mu \mathrm{g} / \mathrm{mL}$ SigmaAldrich), was used as a positive control to evaluate the responsiveness of PBMCs. To facilitate co-stimulation, $1 \mu \mathrm{g} / \mathrm{mL}$ anti-human CD28 (R\&D Systems) was added to the cell cultures. Brefeldin A $(10 \mu \mathrm{g} / \mathrm{mL}$; Sigma-Aldrich) was added after the first $3 \mathrm{~h}$ in to inhibit cytokine secretion.

\section{Th1, Th17 and Treg Immune Responses}

The percentage of Th1, Th17 and Treg lymphocytes was determined by flow cytometric analysis. Th1 lymphocytes were identified as IFN $\gamma$-, IL-2-secreting, Tbet-expressing CD4+ T cells; Th17 lymphocytes as IL17- , IL-21-secreting, ROR $\gamma \mathrm{T}$-expressing CD4+ T cells; Treg lymphocytes as $\mathrm{CD} 25^{\text {high }}$, FoxP3-expressing CD4+ T cells. 
The IFX concentration of $50 \mu \mathrm{g} / \mathrm{mL}$ was chosen after setting a titration test with increasing concentrations of the drug and on the basis of the IFX median serum concentrations $1 \mathrm{~h}$ after infusion (peak serum concentration: $39.9-219.1 \mu \mathrm{g}$ ) [17].

\section{Flow Cytometry}

The following monoclonal antibodies (mAbs) were used: CD4 PE-Cy7, IL-2 PE, CD25 ECD and IFN $\gamma$ FITC (Beckman Coulter, Milan, Italy); Foxp3 PECy5, T-bet PerCP Cy5.5 and ROR $\gamma$ T PE (eBiosciences, San Diego, CA, USA); IL-21 APC and IL-17A FITC (Biolegend, San Diego, CA, USA); TGF $\beta 1$ PE and IL-10 FITC (R\&D Systems). PBMCs were incubated 15 min with the mAbs for the detection of cell surface antigens. Then cells were permeabilized $30 \mathrm{~min}$ with the Fixation/Permeabilization buffer (eBiosciences), and further stained with the antibodies for the detection of intracellular transcription factors and cytokines.

Lymphocyte population was gated based on the basis of forward and side scatter properties, and further gated for CD4 expression; at least 20,000 events were acquired within the CD4 gate. The samples were acquired using a Gallios flow cytometer and data were analysed using Kaloosa software (both Beckman Coulter).

\section{Statistical Analysis}

As data were normally distributed, procedures were based on parametric analyses. Comparisons between the different groups were performed using unpaired Student's T Test for unequal variances with a two tailed $\mathrm{P}$ value. Significance was set at $P<0.05$. Statistical analysis was performed using GraphPad Prism Software (GraphPad Software, San Diego, CA, USA).

\section{Results}

\section{Patient Demographic and Clinical Details}

We enrolled 20 consecutive RA patients (16 females; mean age $61.3 \pm$ 12.2 years; mean disease duration $13.4 \pm 7.2$ years) successfully treated with IFX $3 \mathrm{mg} / \mathrm{kg}$ every 8 weeks, and 20 consecutive RA patients (15 
females; mean age $57.0 \pm 12.2$ years; mean disease duration $18.1 \pm$ 9.5 years) who discontinued IFX due to inefficacy (11 cases) or adverse events ( 9 cases). A total of 15 patients were positive for anticitrullinated protein antibodies (ACPAs), and 11 responders and 15 non-responders were positive for rheumatoid factor (RF). During IFX treatment, anti-nuclear antibodies (ANAs) appeared in 12 responders and 17 non-responders (Table 1). No clinical correlations were found. The IFX non-responders were treated with abatacept $10 \mathrm{mg} / \mathrm{kg}$ every 4 weeks (13 subjects), tocilizumab $8 \mathrm{mg} / \mathrm{kg}$ every 4 weeks (5 subjects), etanercept $50 \mathrm{mg}$ once a week (1 subject), or certolizumab pegol $200 \mathrm{mg}$ every other week ( 1 subject) as the second ( 8 subjects), third ( 8 subjects), or fourth biological agent (4 subjects). The patients in both treated groups concomitantly received the allowed Disease-modifying antirheumatic drugs (DMARDs) and corticosteroids.

\section{Th1 and Th17}

In order to evaluate whether the immunogenic effects of IFX are mediated by Th1 and Th17 lymphocytes, these subpopulations were analysed in RA patient groups (treatment-naïve, IFX responders, IFX non-responders) and in healthy controls, under unstimulated and IFXstimulated conditions.

Under unstimulated conditions, the percentage of both IFN $\gamma$-secreting, Tbet-expressing, CD4+ T cells and IL-2-secreting, Tbet-expressing, CD4+ T cells was significantly lower in healthy controls than in RA patient groups. Furthermore, there was a significantly higher proportion of IFN $\gamma$ - and IL-2-secreting Th1 cells in naïve RA patients compared to both IFX-responders and non-responders (Fig. 1a, b). Th17 lymphocytes (IL-17-secreting, ROR $\gamma \mathrm{T}$-expressing CD4+ T cells) showed a similar trend, being significantly higher in RA patients than in healthy subjects, and significantly higher in naïve patients than in IFX responders $(P<0.05)$ (Fig. 1c).

Fig. 1

Percentages of Th1 and Th17 subpopulations under unstimulated, IgG1kappa-stimulated, and IFX-stimulated conditions in RA patients and healthy controls. Th1 lymphocytes were identified as IFN $\gamma-$ (a) or IL2producing, T-bet-expressing, CD4+ T cells (b), and Th17 lymphocytes as 
IL17- (c) or IL21-producing, RoryT-expressing CD4+ T cells (d). The frequency of each subset of CD4+ T cells was compared among healthy controls $(n=10)$, treatment-naïve $(n=15)$, IFX responders $(n=10)$, and IFX non-responders $(n=20)$. Results are shown as Box and Whisker Plot (Tukey's method). ${ }^{*} p<0.05 ; * * p<0.01$ (Student's t test)
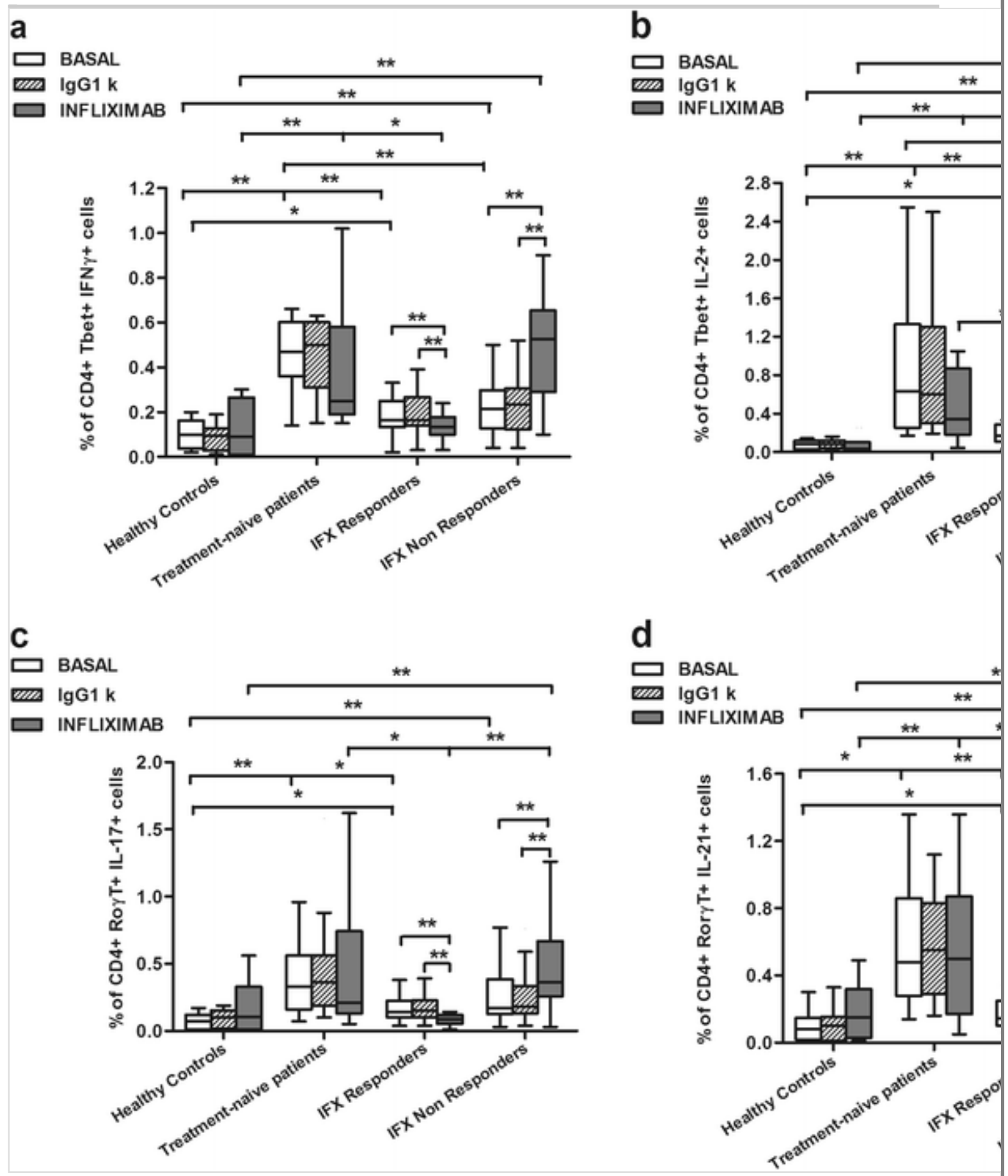

As IL-21 plays an important role in Th17 differentiation and expansion by amplifying Th17 responses, we evaluated the production of this cytokine by Th17 cells. 
As expected, healthy controls had the lowest percentage of IL-21secreting, ROR $\gamma \mathrm{T}$-expressing CD4+ T cells and treatment-naïve RA patients were characterized by a significantly higher percentage of these cells than IFX responders $(P<0.01)$ (Fig. 1d).

The IFX stimulation of PBMCs from the three groups of RA patients and healthy controls led to completely different immune profiles, with the IFX non-responders developing IFX-specific Th1-Th17 responses.

IFX stimulation significantly increased both IFN $\gamma$-secreting, Tbetexpressing CD4+ T cells and IL-2-secreting, Tbet-expressing CD4+ T cells in non-responder patients $(P<0.01)$, but significantly diminished these cells $(P<0.05)$ in responder patients compared to unstimulated condition. In contrast, no significant differences were detected in healthy individuals and in naïve patients, even if a trend in the reduction of Th1 lymphocytes was observed in naïve patients (Fig. 1a, b).

Similarly, IL17- and IL21-secreting, ROR $\gamma$ T-expressing CD4+ T cells in IFX treated cultures were significantly augmented in non-responders and decreased in responders compared to unstimulated conditions $(P<$ 0.05 , in both the cases); on the contrary, no significant variations were seen in naïve patients and healthy individuals (Fig. 1c, d).

Addition of non-specific human IgG belonging to the same isotype of IFX (IgG1 kappa) did not alter the percentage of Th1 and Th17 subpopulations in any of the groups, suggesting that the effects reported were IFX-specific (Fig. 1a, b, c, d).

Finally, we verified whether the increase in Th1 and Th17 responses correlated with the onset of adverse events or the inefficacy of IFX therapy in IFX non-responders. We observed that the percentage of IL17-secreting, ROR $\gamma$ T-expressing CD4+ T cells was significantly higher in the patients who discontinued therapy because of inefficacy than in those who discontinued it because of adverse events, under both unstimulated and IFX-stimulated conditions $(P<0.05$ and $P<0.01$; Fig. 2). On the contrary, there was no correlation between discontinuation for inefficacy or adverse effects and the increase in the percentage of Th1 lymphocytes (not shown). 


\section{Fig. 2}

Percentages of Th17 T lymphocytes (IL17, RoryT-expressing CD4+ T cells) under unstimulated, IgG1kappa-stimulated, and IFX-stimulated conditions in the IFX non-responder patients who discontinued therapy because of inefficacy $(n=11)$ or adverse effects $(N=9)$. Results are shown as Box and Whisker Plot (Tukey's method). ${ }^{*} p<0.05 ;{ }^{* *} p<0.01$ (Student's $t$ test)

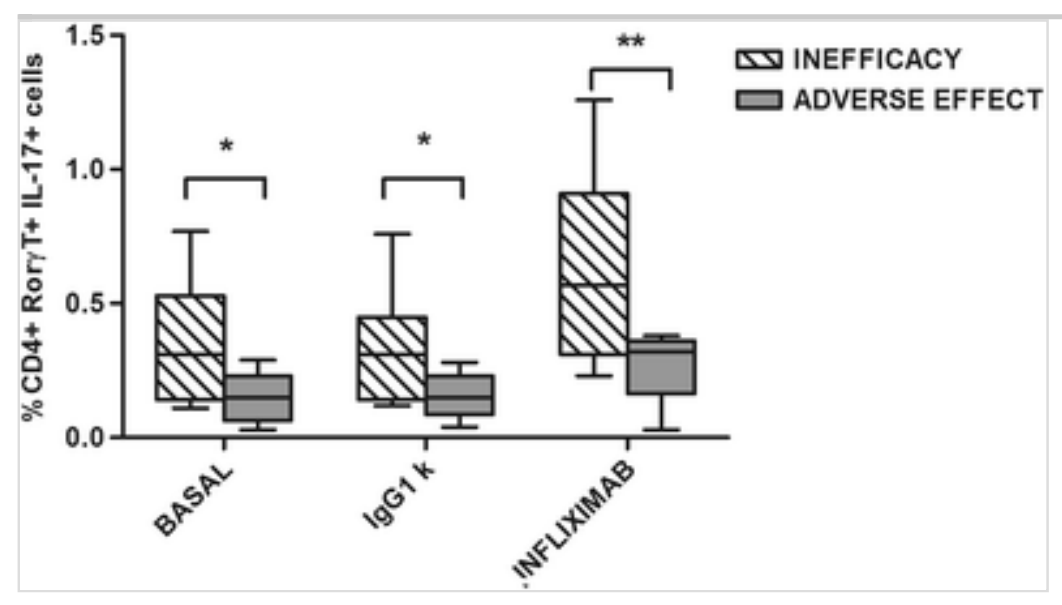

\section{Treg}

As the number and functionality of Treg cells are altered in RA patients, we investigated the effect of IFX treatment on this T cell subset. Under unstimulated conditions, the percentage of CD25 $5^{\text {high }}$, FoxP3-expressing CD4+ T cells was higher in healthy controls than in treatment-naïve and IFX non-responders patients $(P<0.01$ in both the cases). Moreover, these cells were increased in IFX-responders compared to treatment-naïve patients $(P<0.01)$ and IFX nonresponders $(P<0.05)$. Instead, no statistically significant difference was observed between healthy controls and responders (Fig. 3a).

\section{Fig. 3}

Regulatory $\mathrm{T}$ lymphocytes under unstimulated, IgG1kappa-stimulated, and IFX-stimulated conditions in RA patients and healthy controls. a shows the percentage of total Treg lymphocytes, $\mathbf{b}$ the percentage of TGFß-producing Treg lymphocytes, and $\mathbf{c}$ the percentage of IL-10producing Treg lymphocytes. The frequency of Tregs, IL-10-producing Tregs, and TGF $\beta$-producing Tregs was compared among healthy controls $(n=10)$, treatment-naïve $(n=15)$, IFX responders $(n=10)$, and IFX non- 
responders $(n=20)$. Results are shown as Box and Whisker Plot (Tukey's method). ${ }^{*} p<0.05 ;{ }^{* *} p<0.01$ (Student's t test)
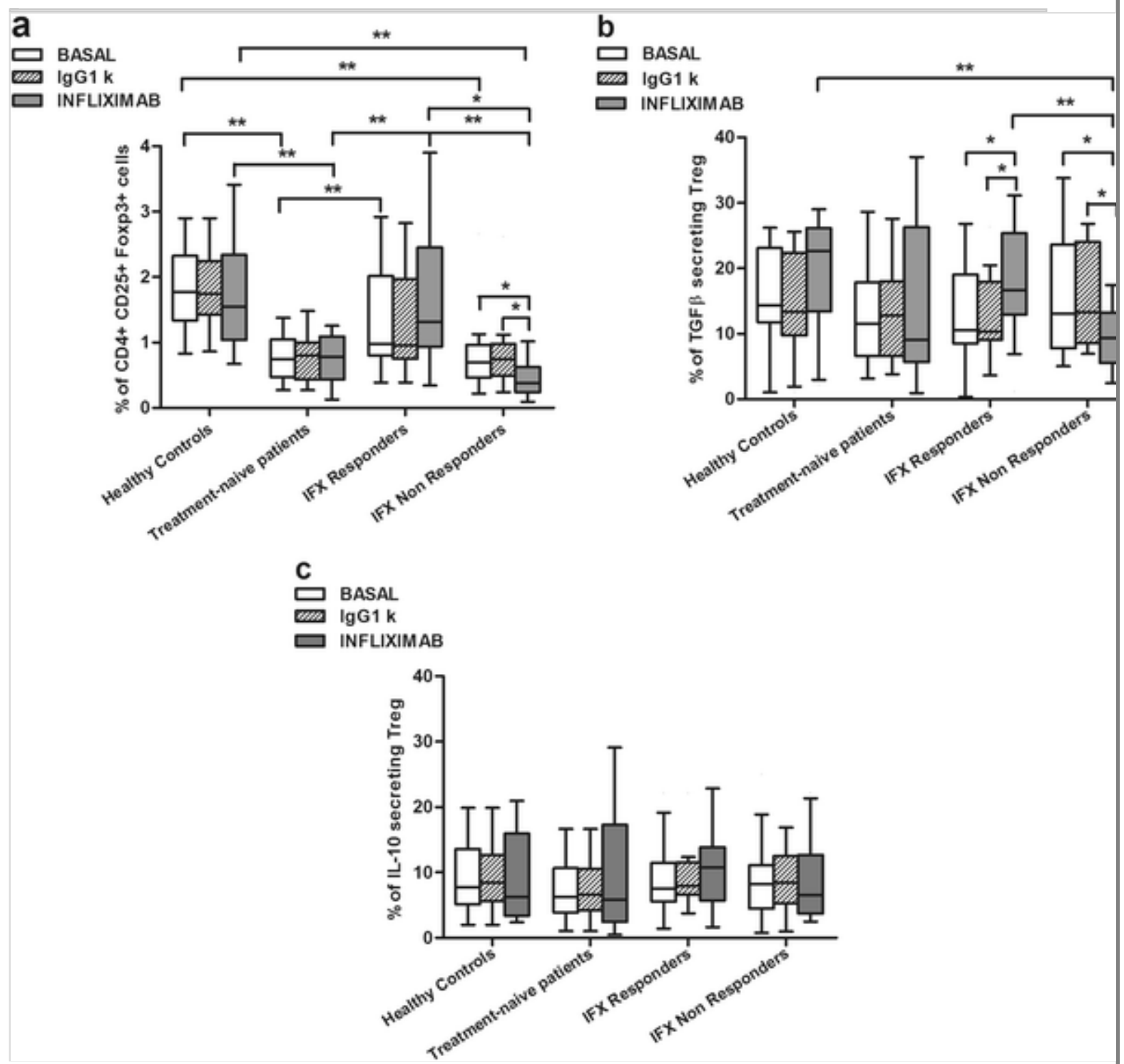

The exposure of PBMCs to IFX led to a significant reduction in Treg cells compared to unstimulated condition only in the samples taken from non-responders $(P<0.05)$. As TGF $\beta$ and IL-10 mediate the suppressive action of Tregs, we evaluated their production by Tregs after IFX exposure in all the groups. IFX significantly reduced the levels of TGF $\beta$-producing Treg cells in non-responders $(P<0.05)$ and increased them in responders $(P<0.05)$, compared to unstimulated conditions; no difference in the number of Treg cells or in the frequency of TGF $\beta$-secreting Tregs was observed in the IFX-stimulated PBMCs of treatment-naïve patients or healthy controls (Fig. 3b). Furthermore, there was no change in the frequency of IL10-secreting Tregs in any of 
the groups (Fig. 3c). The addition of non-specific human IgG did not alter the percentage of Tregs, TGF $\beta$-producing Tregs, or IL10producing Tregs in any of the groups (Fig. 3a, b, c).

\section{Th17/Treg Ratio}

Alterations in the Th17/Treg ratio have been reported in RA patients and, under unstimulated conditions, we found that the ratio was significantly higher in all of the patient groups than in healthy controls. Furthermore, both naïve and non responder patients showed a significantly higher Th17/Treg ratio than IFX responders. Upon Infliximab stimulation, the Th17/Treg ratio significantly increased in non-responders and decreased in responders, compared to unstimulated or IgG1 kappa-stimulated conditions. In both healthy subjects and in naïve patients a trend in increase of the Th17/Treg ratio was observed, but statistical significance was not reached (Fig. 4).

\section{Fig. 4}

Th17/Treg ratio under unstimulated, IgG1kappa-stimulated, and IFXstimulated conditions in RA patients and healthy controls. The ratio was compared among healthy controls $(n=10)$, treatment-naïve $(n=15)$, IFX responders $(n=10)$, and IFX non-responders $(n=20)$. Data represent mean \pm SE. $* p<0.05 ; * * p<0.01$ (Student's t test)

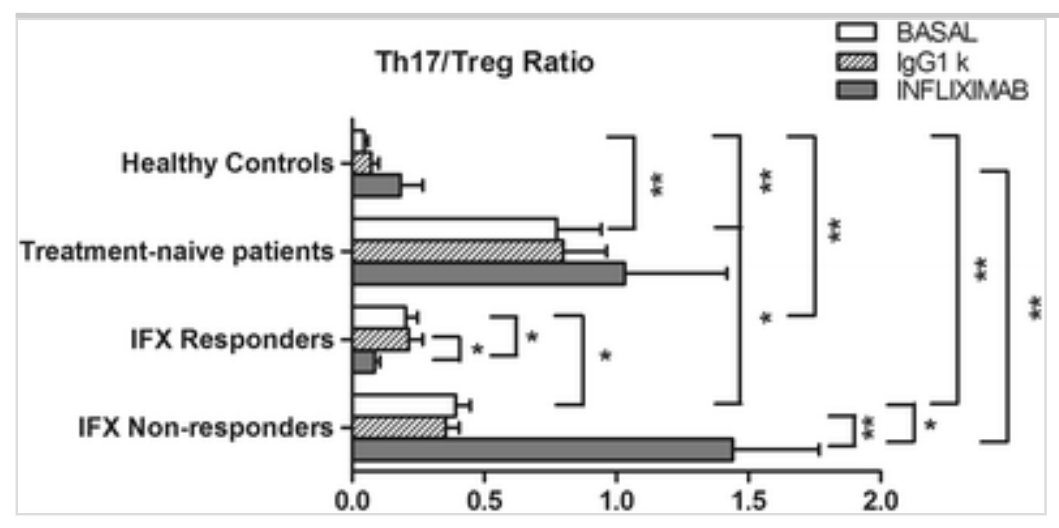

\section{Discussion}

Biological drugs can behave as antigens and be presented via the MHC II complex, inducing the differentiation of naïve T cells into Th1, Th2 or Th17 lymphocytes depending on the cytokine microenvironment [18, 19]. A lack of immunological tolerance (a distinctive trait of 
autoimmune diseases) may contribute to the expansion of the Th17 cell compartment, and it can be hypothesised that the breakdown of peripheral tolerance during rheumatic diseases shifts immunological responses towards a Th17 profile.

Antibodies reacting against biological agents have been found in the serum of rheumatic patients failing biological therapy. The antibodies produced may belong to different isotypic classes (IgM, IgG, and IgE), thus activating different immunological effector pathways $[6,20]$.

Among TNF $\alpha$ blockers, IFX (a chimeric monoclonal antibody containing $25 \%$ of mouse-derived proteins) induces the formation of anti IFX antibodies in a high percentage of the patients treated with this drug [21], whereas adalimumab and etanercept are less immunogenic because of their different molecular structures and administration routes [22]. The concomitant use of traditional DMARDs is recommended during anti-TNF therapy because it reduces the immunogenicity of all biological drugs [23].

However, very little is known about the activation of an adaptive response involving Th1 or Th17 lymphocytes by TNF $\alpha$ blockers. The published data are conflicting possibly because they relate to different patient populations, cell culture conditions and methodologies.

Given the still limited knowledge of the immunogenicity of anti-TNF drugs, we studied Th1, Th17 and Treg responses in different subsets of RA patients (patients discontinuing IFX treatment because of ineffectiveness or clearly drug-related adverse events, IFX responders, and treatment-free RA patients) and healthy controls.

We found that treatment-naïve RA patients have a higher percentage of Th1 and Th17 lymphocytes than healthy donors, which is in line with the findings of various studies suggesting that these cells contribute to the pathophysiology of the disease [24-27]. Moreover, the percentage of Th1 and Th17 lymphocytes was significantly greater in treatmentnaïve RA patients than in IFX-responders.

A recent study on IFX-treated RA patients found a greater reduction in the chemokines belonging to the Th1 than to the Th2 axis [28]. Other 
authors have instead observed that a 6 weeks' treatment increases the IFN $\gamma /$ IL-4 ratio in IFX responders, but does not seem to affect the Th1/Th2 ratio in non-responder patients [29]. However, in the latter study the Th1 and Th2 responses were examined after prolonged culture of PBMCs in presence of Th1 polarising cytokines, such as IL-12 and IL-18. On the other hand, the treatment with other biological agents (adalimumab and etanercept) was reported to significantly decrease the percentage of Th1 and Th17 cells in comparison with pre-treatment levels $[24,26,30]$.

Upon IFX stimulation, we observed a significant increase in the percentage of Th1 and Th17 lymphocytes in non-responder patients, compared to unstimulated condition. Interestingly, IFX induced IL-21 production by Th17 cells in non-responders. This cytokine plays an important role in RA, as it is found at high levels in synovial fluid and serum of RA patients and significantly stimulates Th17 proliferation [31]. On the contrary, incubation with IFX repressed Th1 and Th17 responses in IFX responders, but did not significantly affect these responses in healthy controls or treatment-naïve patients (although there was a trend towards a reduction in Th1 responses in naïve patients).

A study has reported that, in healthy subjects, IFX suppresses Th1 responses more markedly than Th17 response. However, in this study CD4 T lymphocytes from healthy subjects were cultured under polarizing conditions that specifically induced Th1 or Th17 differentiation [32].

The increase in Th1 responses was not significantly associated with either inefficacy or adverse events, but the patients who discontinued IFX because of inefficacy showed a significantly greater increase in Th17 responses than those who discontinued the therapy because of adverse events.

The results obtained suggested that IFX may induce the paradoxical activation of Th1 and Th17 responses in IFX non-responders.

We also investigated whether an impairment of Treg lymphocytes may contribute, at least in part, to activation of Th1 and Th17 responses induced by IFX treatment. Several studies on RA patients have reported 
alterations in the frequency and functioning of Treg cells, as well as in the Th17/Treg balance. The proportion of Tregs in peripheral blood of early active RA patients prior to disease modifying treatment is smaller than in healthy controls and also their suppressive functions are altered. Furthermore, anti-rheumatic biological therapy (including IFX therapy) can increase the proportion of Tregs, restore their functions, and shift the Th17/Treg balance in favour of Tregs [24, 33-36]. In agreement with these studies, we observed a significantly lower percentage of Tregs and TGF $\beta$-secreting Treg in naïve patients than in healthy controls and an increased percentage of these subpopulation in IFXresponders compared to naïve and non-responder subjects. In addition, the exposure to IFX of PBMCs from non-responders further decreased Treg frequency and TGF $\beta$ secretion. IFX restored the Th17/Treg balance in favour of Tregs in responders, whereas in non- responders the Th17/Treg ratio was even increased. There was therefore an inverse correlation between the percentage of Tregs and the percentage of Th1 and Th17 cells.

Accumulating evidence suggests the reciprocal cross-regulation of Th17 and Tregs by means of different regulatory mechanisms [37], and a subset of Tregs able to convert into pathogenic Th17 lymphocytes under inflammatory conditions has recently been identified [38]. Further studies are necessary to better elucidate the effect of IFX on Treg/Th17 balance.

\section{Conclusions}

A considerable number of RA patients gains no benefit or experiences adverse events after starting anti-TNF $\alpha$ therapy. The economic burden of prescribing potentially dangerous or unnecessary treatments prompted us to study the mechanisms responsible for treatment failure. Subjects with autoimmune diseases such as RA have impaired peripheral tolerance, which could favour the development of an aberrant immunological response against a wide range of antigens, and the findings of this in vitro study indicate that IFX may activate aberrant immunological responses in non-responders to IFX treatment. The development of Th1 or Th17 responses following sensitisation to biological agents may even worsen the inflammation related to the 
underlying disease, and further studies of the Th cell network could improve our understanding of the role of anti-TNF agents in unbalancing the immune system of RA patients.

\section{Acknowledgments}

We would like to thank Dr. Donata Dell'Acqua for her technical support and all residents and consultants for their kind collaboration. This study was supported by FIRA (Italian Foundation focused on Rheumatoid Arthritis Research), which did not play any role in conducting the study, deciding on the analyses, or writing the manuscript. The authors declare no competing interest

\section{References}

1. Purcell RT, Lockey RF. Immunologic responses to therapeutic biologic agents. J Investig Allergol Clin Immunol. 2008;18:335-42.

2. Harding FA, Stickler MM, Razo J, DuBridge RB. The immunogenicity of humanized and fully human antibodies: residual immunogenicity resides in the CDR regions. MAbs. 2010;2:256-65.

3. Fiorino G, Danese S, Pariente B, Allez M. Paradoxical immunemediated inflammation in inflammatory bowel disease patients receiving anti-TNF-alpha agents. Autoimmun Rev. 2014;13:15-9.

4. Krieckaert CL, Bartelds GM, Wolbink GJ. Therapy: immunogenicity of biologic therapies: we need tolerance. Nat Rev Rheumatol. 2010;6:558-9.

5. Radstake TR, Svenson M, Eijsbouts AM, van den Hoogen FH, Enevold C, van Riel PL, et al. Formation of antibodies against infliximab and adalimumab strongly correlates with functional drug levels and clinical responses in rheumatoid arthritis. Ann Rheum Dis. 2009;68:1739-45.

6. Vultaggio A, Matucci A, Nencini F, Pratesi S, Parronchi P, Rossi $\mathrm{O}$, et al. Anti-infliximab $\operatorname{IgE}$ and non-IgE antibodies and induction 
of infusion related severe anaphylactic reactions. Allergy. 2010;65:657-61.

7. Pascual-Salcedo D, Plasencia C, RamiroS, Nuño L, Bonilla G, Nagore D, Ruiz Del Agua A, Martínez A, Aarden L, Martín-Mola E, Balsa A. Influence of immunogenicity on the efficacy of long-term treatment with infliximab in rheumatoid arthritis. Rheumatology (Oxford). 2011;1445-52.

8. Atzeni F, Talotta R, Salaffi F, Cassinotti A, Varisco V, Battellino $\mathrm{M}$, et al. Immunogenicity and autoimmunity during anti-TNF therapy. Autoimmun Rev. 2013;12:703-8.

9. Torres MJ, Chaves P, Doña I, Blanca-López N, Canto G, Mayorga C, et al. T-cell involvement in delayed-type hypersensitivity reactions to infliximab. J Allergy Clin Immunol. 2011;128:1365-7.

10. Aletaha D, Neogi T, Silman AJ. Rheumatoid arthritis classification criteria. an American College of

Rheumatology/European League Against Rheumatism Collaborative Initiative. Arthritis Rheum. 2010;6:2569-81.

\section{Krieckaert CL, Nurmohamed MT, Wolbink GJ. Methotrexate} reduces immunogenicity in adalimumab treated rheumatoid arthritis patients in a dose dependent manner. Ann Rheum Dis. 2012;71:1914 -5 .

12. García-Piñeres A, Hildesheim A, Dodd L, Kemp TJ, Williams $\mathrm{M}$, Harro $\mathrm{C}$, et al. Cytokine and chemokine profiles following vaccination with human papillomavirus type $16 \mathrm{~L} 1$ virus-like particles. Clin Vaccine Immunol. 2007;14:984-9.

13. Purvis S, Asaad R, Valerio I, Sha BE, Landay AL, Lederman MM. Levels of proinflammatory cytokines in plasma after pneumoccoccal immunization in human immunodeficiency virus type 1-infected patients. Clin Diagn Lab Immunol. 1999;6:427-8. 
14. Weigmann B, Jarman ER, Sudowe S, Bros M, Knop J, ReskeKunz AB. Induction of regulatory $\mathrm{T}$ cells by leflunomide in a murine model of contact allergen sensitivity. J Investig Dermatol. 2006;126:1524-33.

\section{Chong AS, Ma LL, Shen J, Blinder L, Yin DP, Williams JW.} Modification of humoral responses by the combination of leflunomide and cyclosporine in Lewis rats transplanted with hamster hearts. Transplantation. 1997;64:1650-7.

16. Belmar NA, Lombardo JR, Chao DT, Li O, Ma X, Pong-Afar M, et al. Dissociation of the efficacy and cytokine release mediated by an Fc-modified anti-CD3 mAb in a chronic experimental autoimmune encephalomyelitis model. J Neuroimmunol. 2009;212:65-73.

17. St Clair EW, Wagner CL, Fasanmade AA, Wang B, Schaible T, Kavanaugh A, et al. The relationship of serum infliximab concentrations to clinical improvement in rheumatoid arthritis: results from ATTRACT, a multicenter, randomized, double-blind, placebo-controlled trial. Arthritis Rheum. 2002;46:1451-9.

18. Weber CA, Mehta PJ, Ardito M, Moise L, Martin B, De Groot AS. T cell epitope: friend or foe? Immunogenicity of biologics in context. Adv Drug Deliv Rev. 2009;61:965-76.

19. Azfali B, Lombardi G, Lechler I, Lord GM. The role of T helper 17 (Th17) and regulatory T cells (Treg) in human organ transplantation and autoimmune disease. Clin Exp Immunol. 2007;148:32-46.

20. Svenson M, Geborek P, Saxne T, Bendtzen K. Monitoring patients treated with anti-TNF-alpha biopharmaceuticals: assessing serum infliximab and anti-infliximab antibodies. Rheumatology. 2007;46:1828-34.

21. Noman M, Vermeire S, Van Assche G, D' Haens G, Carbonez A, Rutgeerts P. Influence of immunogenicity on the long-term 
efficacy of infliximab in Crohn's disease. N Engl J Med. 2003;348:601-8.

22. Van de Putte LBA, Atkins C, Malaise M, Sany J, Russell AS, van Riel PL, et al. Efficacy and safety of adalimumab as monotherapy in patients with rheumatoid arthritits for whom previous disease modifying antirheumatic drug treatment has failed. Ann Rheum Dis. 2004;63:508-16.

23. Krieckaert CL, Bartelds GM, Lems WF, Wolbink GJ. The effect of immunomodulators on the immunogenicity of TNF-blocking therapeutic monoclonal antibodies: a review. Arthritis Res Ther. 2010;12:217.

24. Lina C, Conghua W, Nan L, Ping Z. Combined treatment of etanercept and MTX reverses Th1/Th2, Th17/Treg imbalance in patients with rheumatoid arthritis. J Clin Immunol. 2011;31:596 -605 .

25. James E, Rieck M, Pieper J, Gebe JA, Yue BB, Tatum M, et al. Citrulline specific Th1 cells are increased in rheumatoid arthritis and their frequency is influenced by disease duration and therapy. Arthritis Rheum. 2014;66:1712-22.

26. Leipe J, Grunke M, Dechant C, Reindl C, Kerzendorf U, Schulze-Koops H, et al. Role of Th17 cells in human autoimmune arthritis. Arthritis Rheum. 2010;62:2876-85.

27. van Hamburg JP, Mus AM, Colin EM, Hazes JM, Dolhain RJ, Lubberts E. Th17 cells, but not Th1 cells, from patients with early rheumatoid arthritis are potent inducers of matrix metalloproteinases and proinflammatory cytokines upon synovial fibroblast interaction, including autocrine interleukin-17A production. Arthritis Rheum. 2011;63:73-83.

28. Eriksson C, Rantapää-Dahlqvist S, Sundqvist KG. Changes in chemokines and their receptors in blood during treatment with the 
TNF inhibitor infliximab in patients with rheumatoid arthritis. Scand J Rheumatol. 2013;42:260-5.

29. Kawashima M, Miossec P. Effect of treatment of rheumatoid arthritis with infliximab on IFN $\gamma$, IL4, T-bet, and GATA-3 expression: link with improvement of systemic inflammation and disease activity. Ann Rheum Dis. 2005;64:415-8.

30. Aravena O, Pesce B, Soto L, Orrego N, Sabugo F, Wurmann P, et al. Anti-TNF therapy in patients with rheumatoid arthritis decreases Th1 and Th17 cell populations and expands IFN- $\gamma$ producing NK cell and regulatory $\mathrm{T}$ cell subsets. Immunobiology. 2011;216:1256-63.

31. Li W, Xi Y, Xie C, Jiang T, Zhang J, Dong C, et al. Regulatory immune responses induced by IL-1 receptor antagonist in rheumatoid arthritis. Mol Immunol. 2011;49:290-6.

32. Kanayama K, Nakamura K, Ogino H, Sumida Y, Ihara E, Akiho $\mathrm{H}$, et al. Th1 response are more susceptible to infliximab-mediated immunosuppression than Th17 response. Dig Dis Sci. 2011;56:3525 -33 .

33. Ehrenstein MR, Evans JG, Singh A, Moore S, Warnes G, Isenberg DA, et al. Compromised function of regulatory $\mathrm{T}$ cells in rheumatoid arthritis and reversal by anti-TNFalpha therapy. J Exp Med. 2004;200:277-85.

34. Lawson CA, Brown AK, Bejarano V, Brown AK, Bejarano V, Douglas $\mathrm{SH}$, et al. Early rheumatoid arthritis is associated with a deficit in the $\mathrm{CD} 4+\mathrm{CD} 25$ high regulatory $\mathrm{T}$ cell population in peripheral blood. Rheumatology (Oxford). 2006;45:1210-7.

35. Nadkarni S, Mauri C, Ehrenstein MR. Anti-TNF-alpha therapy induces a distinct regulatory $\mathrm{T}$ cell population in patients with rheumatoid arthritis via TGF-beta. J Exp Med. 2007;204:33-9. 
36. Nie H, Li R, Guo TB, He D, Fang L, Liu X, et al.

Phosphorylation of FOXP3 controls regulatory $\mathrm{T}$ cell function and is inhibited by TNF- $\alpha$ in rheumatoid arthritis. Nat Med. 2013;19:322 -8 .

37. Nistala K, Adams S, Cambrook H, Ursu S, Olivito B, de Jager $\mathrm{W}$, et al. Th17 plasticity in human autoimmune arthritis is driven by the inflammatory environment. Proc Natl Acad Sci U S A. 2010;107 (33):14751-6.

38. Joller N, Kuchroo VK. Good guys gone bad: exTreg cells promote autoimmune arthritis. Nat Med. 2014;20:15-7. 